\title{
HERANÇA DIGITAL: O PRECEDENTE ALEMÃO E OS DIREITOS FUNDAMENTAIS À INTIMIDADE E PRIVACIDADE
}

\section{Marcos Rodrigo Maichaki ${ }^{1}$}

Resumo: Os direitos fundamentais à intimidade e à privacidade constituem pilares do Estado Democrático de Direito. Atualmente fala-se na chamada herança digital, que é a possibilidade de que os herdeiros de uma pessoa falecida tenham acesso aos seus arquivos digitais e conversas armazenadas em redes sociais. Recentemente, uma decisão do Tribunal Federal Alemão deferiu aos pais de uma garota falecida pleno direito de acesso à sua conta no Facebook. O presente artigo busca, por meio do método dedutivo, analisar se a herança digital fere ou não o direito à privacidade da pessoa falecida, segundo o direito brasileiro.

Palavras-chave: direitos fundamentais, intimidade, privacidade, herança digital, Tribunal Federal Alemão

\section{DIGITAL INHERITANCE: THE GERMAN PRECEDENT AND FUNDAMENTAL RIGHTS TO INTIMACY AND PRIVACY}

Abstract: The fundamental rights to intimacy and privacy are pillars of the Democratic Rule of Law. There is talk today of so-called digital inheritance, which is the possibility that the heirs of a deceased person have access to their digital files and conversations stored on social networks. Recently, a decision of the German Federal Court has granted the parents of a deceased girl full right of access to her Facebook account. The present article seeks, through the deductive method, to analyze whether or not the digital inheritance violates the right to privacy of the deceased person, according to Brazilian law.

Key-words: fundamental rights; intimacy; privacy; digital inheritance; German Federal Court

\section{INTRODUÇÃO}

O direito, hodiernamente, é constantemente confrontado com situações inovadoras, as quais são fruto das incessantes evoluções que ocorrem no contexto da modernidade, especialmente aquelas concernentes à tecnologia informática e à internet, que propiciaram a criação das populares "redes sociais", no âmbito das quais surgem formas sempre novas de interação e relacionamento entre as pessoas nas mais diversas partes do planeta.

Notadamente no campo das redes sociais, devido à sua ampla popularidade, abrangência e à efervescência das interações que proporcionam, é que se reclamam uma

\footnotetext{
${ }^{1}$ Bacharel em Direito pela Universidade do Norte do Paraná - UENP. Funcionário do Tribunal de Justiça do Estado do Paraná desde 2010, com atuação na comarca de Wenceslau Braz-PR. É mestrando no Programa de Pós-Graduação em Ciência Jurídica da Universidade Estadual do Norte do Paraná - UENP, cuja área de concentração é Teorias da Justiça: Justiça e Exclusão; Linha de Pesquisa: Função Política do Direito. E-mail: mrmaichakiwb@gmail.com
}

Revista Brasileira de Direito Civil em Perspectiva | e-ISSN: 2526-0243| Porto Alegre | v. 4 | n. 2

p. $136-155$ | Jul/Dez. 2018 
presença e uma dinâmica sempre maior do direito, cuja atuação deve mostrar-se apta na tutela dos direitos fundamentais dos participantes e, notadamente, do direito à privacidade.

Nesse contexto, um caso recente chamou a atenção na imprensa mundial. Trata-se da decisão do Tribunal Federal Alemão de Karlsruhe em deferir aos pais de uma garota falecida em 2012 o pleno acesso à sua conta no Facebook. O interesse dos pais baseou-se na busca por elucidar as causas da morte da filha, ocorrida num acidente de trem, em condições pouco claras, sendo que o acesso aos dados e conversas em sua conta na rede social poderia esclarecer se cometera ou não um suicídio.

O fato traz à tona a discussão a respeito da chamada "herança digital", ou seja, o direito que teriam os sucessores de uma pessoa falecida de obterem acesso aos seus dados e arquivos armazenados em mídias digitais e até mesmo em redes sociais. Uma vez reconhecido esse direito na decisão da corte germânica, o presente artigo tem por objetivo analisar a admissibilidade do conceito à luz do direito brasileiro, indagando-se, sobretudo, se representa ou não uma afronta ao direito fundamental à privacidade, no que consiste o problema a ser enfrentado pelo trabalho.

Levam-se em conta, assim, a hipótese de representar o reconhecimento da "herança digital" uma efetiva violação ao direito fundamental à privacidade (da pessoa falecida), ou simplesmente ser-lhe indiferente, uma vez que não se questiona o acesso dos sucessores a cartas, diários e outros documentos físicos que tenham pertencido à pessoa falecida.

O presente artigo desenvolve-se de acordo com o método dedutivo, utilizando-se como premissa geral, que segue exposta no primeiro capítulo, a abordagem do tema relativo ao direito à privacidade e seu regime legal. Como premissa menor, analisa-se, no segundo capítulo, a decisão do Tribunal de Karlsruhe, por meio do comunicado à imprensa disponível no site da referida corte de justiça para, enfim, no terceiro capítulo, analisar os desdobramentos e conclusões relativos aos problemas propostos.

A análise conta ainda com o apoio de material bibliográfico extraído de legislação (brasileira e alemã), dos comunicados emitidos pelo Tribunal Federal Alemão acerca da decisão, artigos científicos, doutrina e informações contidas em páginas da internet.

\section{O DIREITO À PRIVACIDADE}


$\mathrm{O}$ direito à privacidade, segundo assinala a melhor doutrina, decorre da própria natureza do ser humano considerada em toda a sua complexidade. Enquanto ser dotado de razão, vontade e consciência, cada pessoa constitui um microcosmo particular, no âmbito do qual desenvolve seus talentos, opiniões e convicções e no qual faz surgir, maturar e firmar suas decisões pessoais.

Dentre essas decisões, estão aquelas relativas ao que decide externar sobre aquilo que se passa em seu interior, que projetos gestados internamente deseja colocar em prática, que atitudes tomar em determinadas situações, o que dizer ou fazer e o que omitir ou deixar de fazer. Isso tudo compõe uma esfera de liberdade íntima da pessoa, na qual o Estado não deve, a princípio, interferir.

Compre, no entanto, sublinhar a diferença vernacular entre os vocábulos intimidade e privacidade. Enquanto a primeira diz respeito àquilo tudo que é gestado ocultamente no íntimo da psique humana e que num primeiro momento permanece oculto aos demais, a segunda diz respeito àquilo que, desse íntimo, é de alguma forma exteriorizado, mas que o sujeito deseja que não seja de conhecimento público, mas apenas seu ou de quem entenda conveniente. Acerca dessas distinções, assinala com maior clareza Felix Ruiz Alonso (2005, p. 18):

Os atos humanos são preparados ou elaborados na intimidade e, uma vez elaborados, permanecem no interior ou aparecem externamente, segundo forem atos internos ou externos. A preparação do ato humano e aqueles atos humanos que permanecem dentro de nós, sendo apenas internos, pertencem à intimidade. Alguns atos externos, aqueles que a própria natureza reserva ou a pessoa quer reservar e pode reservar para si, por não prejudicarem terceiros, pertencem à privacidade.

Segundo o mesmo autor, "só os atos lícitos são suscetíveis do direito à privacidade pessoal" (2005, p. 18). Prossegue ilustrando que a preparação de um homicídio, por exemplo, enquanto apenas engendrada na mente do criminoso, é um ato íntimo. Uma vez consumado o delito, desejaria o criminoso que seu ato fosse privado, mas não o é, pois é um crime, ou seja, um fato dotado de repercussão social que reclama a atuação da justiça (2005, p. 18).

O direito não se imiscui na intimidade da pessoa, porém é de seu total interesse que essa seja de boa qualidade, pois dela decorrem os atos exteriores dos cidadãos que, consequentemente, trarão reflexos negativos ou positivos na vida em sociedade. Cumpre ao 
Estado, no âmbito que lhe compete, zelar pela boa qualidade da formação de seus cidadãos (ALONSO, 2005, p. 28).

Intimidade e privacidade são protegidas pelo direito no contexto das democracias modernas. No entanto, a proteção da privacidade encontra um maior número de expressões dentro dos ordenamentos jurídicos, uma vez que, enquanto representativa dos atos humanos que adquirem exterioridade, diz respeito àquilo que se pode tornar público ou notório, subtraindo-se da esfera do domínio estritamente individual do sujeito.

Isso não significa, porém, que haja distinção no grau de proteção conferido pelo ordenamento jurídico entre uma esfera e outra, conforme bem assinala Gilberto Haddad Jabur (2005, p. 90, grifo do autor):

Privacidade é círculo de maior raio no qual deitam existência a intimidade e, em círculo menor e mais concêntrico, o segredo. Diversidade técnicoprotetiva entre esses variados graus de riservatezza não há. A Constituição Federal deferiu a mesma tutela à intimidade e à vida privada $\left(\operatorname{art.~} 5^{\circ}, \mathrm{X}\right)$, de sorte a atribuir integral proteção à qualquer forma de reserva pessoal. De maneira que não há valia na distinção vocabular entre intimidade e vida privada, sequencialmente alinhados em obséquio à técnica legislativa de todo louvável à vista de variantes doutrinárias (insuficientes para minorar a tutela de um ou outro), motivo por que o texto se socorreu de ambos substantivos para afiançar o valor que endereçou a qualquer aspecto recôndito da pessoa.

No mesmo sentido se expressa Claudio Luiz Bueno de Godoy (2005, p. 126), assinalando que tanto na proteção do direito à intimidade como na proteção do direito à privacidade, o que se tem é uma garantia contra a intromissão indevida e a proteção da autonomia do indivíduo:

[...] na base do direito à intimidade e à vida privada há um conteúdo principiológico comum, que está na preservação fundamentalmente de um direito de liberdade. Ou seja, [...] não há como procurar um conceito ou um conteúdo para a intimidade e a vida privada sem recorrer à ideia de uma liberdade de não-intromissão e de autonomia, concernentes a aspectos da vida pessoal do indivíduo. Garante-se, pois, com a determinação da inviolabilidade de certos dados da vida da pessoa, sua liberdade de autodeterminação, de tomada de posições ou decisões, sem o que se lhe tolhe a dignidade que está no centro e é o fim de todo o ordenamento.

Passando-se à análise do direito positivo, o direito à privacidade encontra-se abrangido na categoria dos chamados direitos da personalidade, cujas diversas expressões estão insculpidas no texto constitucional pátrio (BRASIL, 1988, online), especialmente no rol de direitos e garantias fundamentais do artigo $5^{\circ}$, nos quais aparecem nos incisos $\mathrm{V}$ (direito de 
resposta), VI (liberdade religiosa), IX (liberdade de expressão), X (proteção da intimidade, da honra e da imagem), XI (inviolabilidade de domicílio) e XII (inviolabilidade de correspondência). Há ainda outras expressões de direitos da personalidade espalhados pelo texto constitucional nacional, tais como o dispositivo que impede a comercialização de órgãos e de sangue (artigo 199, $\S 4^{\circ}$ ).

Para os fins do presente trabalho, cumpre destacar a disposição do inciso XII, a seguir transcrito: "XII - é inviolável o sigilo da correspondência e das comunicações telegráficas, de dados e das comunicações telefônicas, salvo, no último caso, por ordem judicial, nas hipóteses e na forma que a lei estabelecer para fins de investigação criminal ou instrução processual penal” (BRASIL, 1988, online).

Semelhante disposição se encontra no artigo 10 da Lei Fundamental da República Federal da Alemanha (Grundgesetz für die Bundesrepublik Deutschland), que reza: “(1) O sigilo da correspondência, assim como das comunicações postais e da telecomunicação é inviolável" (ALEMANHA, 1949, online). E prossegue, assinalando disciplinando a forma das limitações à inviolabilidade do direito:

(2) Limitações só podem ser ordenadas em virtude de lei. Se a limitação tiver por finalidade proteger a ordem fundamental livre e democrática ou a existência e segurança da Federação e de um Estado federado, a lei pode determinar que a limitação não seja levada ao conhecimento do indivíduo atingido e que, em vez de se seguir a via judiciária, o controle seja efetuado por órgãos principais e auxiliares, nomeados pelos representantes do povo. (ALEMANHA, 1949, online)

Da comparação entre as duas disposições, a nacional e a germânica, depreende-se claramente que aquela é mais restritiva quanto às hipóteses de exceções, permitindo a violação do sigilo unicamente "para fins de investigação criminal e instrução do processo penal", ao passo que a constituição alemã traz disposição bem mais aberta e abrangente, admitindo limitações à garantia constitucional para "proteger a ordem fundamental livre e democrática ou a existência e segurança da Federação e de um Estado federado", expressões estas que podem abranger um número bastante amplo de situações.

No que diz respeito à Constituição Brasileira, tais direitos integram o rol de cláusulas imodificáveis, nos termos do art. 60, $§ 4^{\circ}$, inc. IV (BRASIL, 1988, online). Constituem-se de garantias de que o cidadão está munido contra abusos de terceiros ou mesmo do arbítrio dos governantes. São, ainda, irrenunciáveis e intransmissíveis, nos termos do artigo 11, do Código

Revista Brasileira de Direito Civil em Perspectiva | e-ISSN: 2526-0243| Porto Alegre | v. 4 | n. 2 |

p. $136-155$ | Jul/Dez. 2018 
Civil: “Art. 11. Com exceção dos casos previstos em lei, os direitos da personalidade são intransmissíveis e irrenunciáveis, não podendo o seu exercício sofrer limitação voluntária.” (BRASIL, 2002, online).

Ives Gandra da Silva Martins (2002, p. 5, online) assim explica o sentido dos caracteres de irrenunciabilidade e intransmissibilidade dos direitos da personalidade:

O princípio conforma a lista dos direitos individuais indisponíveis e intransmissíveis, exceção feita àqueles previstos em lei, desde que, implícita ou explicitamente, autorizados pela Constituição.

Em outras palavras, a lei não pode alterar, ao bel-prazer do legislador, direitos indisponíveis ou disponíveis, mas apenas aqueles cuja disponibilidade decorra de princípio geral flexível, admitido pela lei suprema. $O$ que for, explícita ou implicitamente, indisponível na Constituição, não poderá tornar-se disponível por força de lei.

A vedação à limitação voluntária é decorrência natural da indisponibilidade e do pleno exercício de quem os detém.

Sobre os mesmos aspectos, assim discorre Gilberto Haddad Jabur (2005, p. 89), acrescendo ainda que tais direitos são inestimáveis, ou seja, não possuem correspondência em valores pecuniários:

Os direitos personalíssimos são, suficiente e sinteticamente por isso, irrecusáveis e inestimáveis. Irrecusáveis porque, originados ab ovo - daí inatos -, a renúncia é inválida, não os faz fenecer, como defesa é qualquer abdicação traslativa. A Lei Privada registra a irrenunciabilidade, ladeada da instransmissibilidade (CC, art. 11, caput), duas entre diversas manifestações características dos direitos personalíssimos. Inestimáveis, porquanto neles não se encontra ou deles não deflui eqüipolência patrimonial nenhuma, por isso a extrapatrimonialidade que também os marca e distingue.

Em plena consonância com a garantia constitucional prevista no art. $5^{\circ}$, inc. XII, da

Constituição Federal e demais princípios constitucionais, a Lei do Marco Civil da Internet (Lei n. 12.965/2014), assim, dispõe:

Art. $3^{\circ}$ A disciplina do uso da internet no Brasil tem os seguintes princípios: I - garantia da liberdade de expressão, comunicação e manifestação de pensamento, nos termos da Constituição Federal;

II - proteção da privacidade;

III - proteção dos dados pessoais, na forma da lei; (BRASIL, 2014, online).

No artigo $7^{\circ}$, o qual está inserido no Capítulo II - Dos direitos e garantias dos usuários, se estabelece a importante distinção entre a inviolabilidade e sigilo do fluxo das comunicações pela internet e a inviolabilidade e sigilo das comunicações privadas armazenadas, consoante segue transcrito o texto legal respectivo:

Revista Brasileira de Direito Civil em Perspectiva | e-ISSN: 2526-0243| Porto Alegre | v. 4 | n. 2 |

p. 136 - 155 Jul/Dez. 2018 
Art. $7^{\circ} \mathrm{O}$ acesso à internet é essencial ao exercício da cidadania, e ao usuário são assegurados os seguintes direitos:

I - inviolabilidade da intimidade e da vida privada, sua proteção e indenização pelo dano material ou moral decorrente de sua violação;

II - inviolabilidade e sigilo do fluxo de suas comunicações pela internet, salvo por ordem judicial, na forma da lei;

III - inviolabilidade e sigilo de suas comunicações privadas armazenadas, salvo por ordem judicial; (BRASIL, 2014, online).

Por sua vez, o artigo 10, da mencionada lei, faz menção a registros de conexão e de acesso a aplicações de internet, a par de registros de dados pessoais e do conteúdo de comunicações privadas:

Art. 10. A guarda e a disponibilização dos registros de conexão e de acesso a aplicações de internet de que trata esta Lei, bem como de dados pessoais e do conteúdo de comunicações privadas, devem atender à preservação da intimidade, da vida privada, da honra e da imagem das partes direta ou indiretamente envolvidas.

$\S 1^{\circ} \mathrm{O}$ provedor responsável pela guarda somente será obrigado a disponibilizar os registros mencionados no caput, de forma autônoma ou associados a dados pessoais ou a outras informações que possam contribuir para a identificação do usuário ou do terminal, mediante ordem judicial, na forma do disposto na Seção IV deste Capítulo, respeitado o disposto no art. $7^{\circ}$.

$\S 2^{\circ} \mathrm{O}$ conteúdo das comunicações privadas somente poderá ser disponibilizado mediante ordem judicial, nas hipóteses e na forma que a lei estabelecer, respeitado o disposto nos incisos II e III do art. $7^{\circ}$. (BRASIL, 2014, online).

Consoante se depreende da leitura do caput do citado artigo, bem como de seus parágrafos, observa-se que quanto aos registros de conexão e de acesso a aplicações na internet e de dados pessoais, os provedores são obrigados a conservar seus registros, uma vez que serão obrigados a fornecê-los sempre que solicitados; de outra forma, estabelece o $\S 2^{\circ}$ que quanto ao conteúdo das comunicações privadas, há apenas a possibilidade de os provedores serem obrigados a apresentarem o seu teor, levando à conclusão que seu armazenamento não é obrigatório.

Nesse sentido, esclarece Marcelo Frullani Lopes (2016, online):

O Marco Civil deve ser interpretado, portanto, no sentido de que não há imposição aos provedores de aplicações de internet do dever de manter sob sua guarda as comunicações privadas dos usuários. Deve-se resguardar também a possibilidade de que os provedores utilizem criptografia para proteger ainda mais o sigilo. Apenas na hipótese em que os provedores efetivamente guardem essas comunicações, e que não haja algum meio que impeça o acesso ao conteúdo (ex: criptografia), pode-se cogitar na aplicação

Revista Brasileira de Direito Civil em Perspectiva | e-ISSN: 2526-0243| Porto Alegre | v. 4 | n. 2 |

p. $136-155$ | Jul/Dez. 2018 
de sanção judicial para a não disponibilização dessas informações. Caso se demonstre que o provedor não realiza essa guarda, ou que aplica algum meio que impeça o acesso às comunicações passadas dos usuários, a sanção não se coaduna com o Marco Civil da Internet e com a Constituição Federal.

Da leitura dos dispositivos legais acima citados, depreende-se o quão rigorosa é, no direito pátrio, a disciplina do sigilo do conteúdo das comunicações privadas na internet. Passa-se, no segundo capítulo, à análise da decisão do Tribunal Federal da Alemanha, como supracitado.

\section{O PRECEDENTE ALEMÃO}

Recentemente, chamou a atenção em todo o mundo a notícia de que a $3^{\mathrm{a}}$ Câmara Civil, do Tribunal Federal Alemão de Karlsruhe (autos 183/2017) deferiu aos pais de uma garota falecida o pleno direito de acesso a todos os dados de sua conta no Facebook. No comunicado do site do tribunal encontra-se o resumo dos fatos e dos fundamentos da decisão (ALEMANHA, 2018, online).

Narra-se que a garota, identificada pelas iniciais L.W., faleceu no ano de 2012, aos 15 anos de idade, em uma situação que aparentou ser um acidente de trem. Ela havia se registrado na rede social Facebook aos 14 anos de idade no ano anterior, ou seja, em 2011, com o consentimento de seus representantes legais.

Ocorre que, após a sua morte, seus pais tentaram obter acesso aos dados e conversas de sua conta no Facebook, mas a página se havia transformado em "memorial”. Segundo informação atualmente presente na página do Facebook (2018, online), se esclarece que após a morte de uma pessoa sua página é transformada em "memorial", ao qual tem acesso o contato herdeiro, que deve ser selecionado em vida pelo proprietário da conta. No entanto, as ações desse contato herdeiro são limitadas às seguintes: fixar uma publicação no perfil da pessoa, responder às novas solicitações de amizade e alterar a imagem de perfil e a foto de capa. E, caso o proprietário da conta não tenha elegido nenhum herdeiro, a conta não será administrada por ninguém após a sua transformação em memorial.

No caso do processo alemão, o interesse manifestado pelos pais da garota consistia em descobrir se a filha havia ou não cometido suicídio. O acesso à sua conta no Facebook e às conversas travadas por ela na rede social poderiam elucidar ou fornecer indícios para a 
solução da dúvida. Tal interesse, porém, mostrou-se indiferente ao final do processo, pois o que se levou em consideração foi o efetivo direito dos pais de acessarem a conta, independentemente dos fins para os quais o desejavam.

Tendo o tribunal distrital julgado procedente a demanda dos autores, o reclamado (Facebook) recorreu à segunda instância (Kammergericht) e teve seus pedidos rejeitados. Ainda inconformado, o reclamado recorreu ao Tribunal Federal (Bundesgerichtshof), que, por sua vez, também denegou seus pleitos na mencionada decisão do dia 21 de junho de 2018.

Quanto aos fundamentos do decisum, o comunicado do tribunal esclarece, em primeiro lugar, que a sucessão dos direitos da falecida sobre a conta não é impedida pelos termos do contrato entre aquela e o reclamado. Segue o respectivo trecho do comunicado:

Os legatários tem uma reclamação contra o requerido, de negar o acesso à conta de usuário da testadora e ao conteúdo de comunicação da mesma. Isto resulta do contrato de uso entre a filha dos requerentes e o reclamado, o qual impediria a sucessão de todos os direitos em causa de morte segundo $§ 1922$ Art. $1 \mathrm{BGB}^{2}$ aos herdeiros. A possibilidade de herdar tais direitos não vem excluída pelas determinações contratuais. As condições de uso não apresentam sobre tal questão nenhuma regra. As cláusulas sobre o status de memorial não estão incluídas de forma efetiva no contrato. Elas não resistem, além disso, a um controle do conteúdo segundo $§ 307$ Art. 1 e 2 BGB e seriam, por isso, inválidas.

Da essência do contrato também não resulta uma impossibilidade de herança do vínculo contratual; este não é de natureza estritamente pessoal. O caráter estritamente pessoal não resulta das razões tacitamente assumidas e, portanto, imanentes da proteção dos direitos pessoais do parceiro de comunicação da testadora. ${ }^{3}$ (ALEMANHA, 2018, online, tradução livre).

Ou seja, reconheceu-se o direito de herança dos pais de L.W. sobre os direitos contratuais que haviam sido estabelecidos entre ela e o Facebook, não se reconhecendo que referido contrato tivesse caráter estritamente pessoal ao ponto de impedir a transmissão dos direitos, nem mesmo no intuito de proteção dos direitos da personalidade dos parceiros de comunicação de L.W.

\footnotetext{
${ }^{2}$ Sigla que designa o Código Civil Alemão.

${ }^{3}$ Die Erben haben gegen die Beklagte einen Anspruch, ihnen den Zugang zum Benutzerkonto der Erblasserin und den darin vorgehaltenen Kommunikationsinhalten zu gewähren. Dies ergibt sich aus dem Nutzungsvertrag zwischen der Tochter der Klägerin und der Beklagten, der im Wege der Gesamtrechtsnachfolge nach § 1922 Abs. 1 BGB auf die Erben übergegangen ist. Dessen Vererblichkeit ist nicht durch die vertraglichen Bestimmungen ausgeschlossen. Die Nutzungsbedingungen enthalten hierzu keine Regelung. Die Klauseln zum Gedenkzustand sind bereits nicht wirksam in den Vertrag einbezogen. Sie hielten überdies einer Inhaltskontrolle nach $\$ 307$ Abs. 1 und 2 BGB nicht stand und wären daher unwirksam.

Auch aus dem Wesen des Vertrags ergibt sich eine Unvererblichkeit des Vertragsverhältnisses nicht; insbesondere ist dieser nicht höchstpersönlicher Natur. Der höchstpersönliche Charakter folgt nicht aus im Nutzungsvertrag stillschweigend vorausgesetzten und damit immanenten Gründen des Schutzes der Persönlichkeitsrechte der Kommunikationspartner der Erblasserin.
} 
Logo adiante, prossegue a argumentação no mesmo sentido:

É verdade que a assinatura de um contrato de uso com o operador de uma rede social possa ser feita na esperança de que as mensagens entre os participantes da rede fundamentalmente permanecerão de qualquer maneira confidenciais e não serão passadas a terceiros pelo requerido. Contudo, a obrigação contratual do requerido de transmissão e disponibilização de mensagens e outros conteúdos está previamente relacionada à conta. Sua obrigação é, no que se refere ao conteúdo, de transmiti-los não a uma pessoa específica, mas à referida conta do usuário. $\mathrm{O}$ remetente de uma mensagem pode, portanto, até confiar que o requerido a disponibilizará apenas para a conta de usuário escolhida por ele, mas não existe nenhuma garantia de que apenas o titular da conta e não terceiros tomarão conhecimento do conteúdo da conta. Em vida deve-se contar com uma possibilidade de abuso do acesso por terceiros ou com a disponibilização do acesso por parte do titular da conta e no caso de sua morte com a transmissão na forma de herança a outrem do vínculo contratual. ${ }^{4}$ (ALEMANHA, 2018, online, tradução livre).

No trecho da argumentação acima exposto, como foi possível observar, ressaltou-se o fato de que as mensagens enviadas a um determinado destinatário são, na verdade, entregues à sua conta na rede social, nada impedindo que terceiros venham a ter acesso a essas mensagens, até mesmo por iniciativa do titular da conta de destino, o que corrobora a tese segundo a qual as comunicações não gozam de caráter estritamente privado. Reconheceuse, ao mesmo tempo, que as mensagens são passíveis de conhecimento por parte de terceiros no caso de herança, com a sucessão do vínculo contratual.

$\mathrm{Na}$ sequência, se estabelece que no caso de herança não deve haver qualquer restrição de acesso aos conteúdos por parte dos herdeiros, conforme se pode depreender do trecho abaixo:

Uma diferenciação do acesso à conta de acordo com ativos e conteúdos altamente pessoais é aqui excluída. Segundo a valoração legislativa passam também posições de direito com conteúdos altamente pessoais aos herdeiros. Assim são herdados documentos análogos como diários e cartas pessoais, como se deduz do $§ 2047$ Art. 2 e $§ 2373$ item 2 BGB. Não há do ponto de

\footnotetext{
${ }^{4}$ Zwar mag der Abschluss eines Nutzungsvertrags mit dem Betreiber eines sozialen Netzwerks in der Erwartung erfolgen, dass die Nachrichten zwischen den Teilnehmern des Netzwerks jedenfalls grundsätzlich vertraulich bleiben und nicht durch die Beklagte dritten Personen gegenüber offengelegt werden. Die vertragliche Verpflichtung der Beklagten zur Übermittlung und Bereitstellung von Nachrichten und sonstigen Inhalten ist jedoch von vornherein kontobezogen. Sie hat nicht zum Inhalt, diese an eine bestimmte Person zu übermitteln, sondern an das angegebene Benutzerkonto. Der Absender einer Nachricht kann dementsprechend zwar darauf vertrauen, dass die Beklagte sie nur für das von ihm ausgewählte Benutzerkonto zur Verfügung stellt. Es besteht aber kein schutzwürdiges Vertrauen darauf, dass nur der Kontoinhaber und nicht Dritte von dem Kontoinhalt Kenntnis erlangen. Zu Lebzeiten muss mit einem Missbrauch des Zugangs durch Dritte oder mit der Zugangsgewährung seitens des Kontoberechtigten gerechnet werden und bei dessen Tod mit der Vererbung des Vertragsverhältnisses.
}

Revista Brasileira de Direito Civil em Perspectiva | e-ISSN: 2526-0243| Porto Alegre | v. 4 | n. 2

p. 136 - 155 Jul/Dez. 2018 
vista do direito de herança nenhuma razão para tratar conteúdos digitais de forma diferente. ${ }^{5}$ (ALEMANHA, 2018, online, tradução livre).

Trata-se de um ponto importante, com menção às respectivas disposições do Código Civil Alemão, segundo o qual também a documentação com conteúdo altamente pessoal é transmissível aos herdeiros. Uma vez que cartas e diários do de cujus, ainda que com conteúdos altamente pessoais, são transmissíveis, sendo que a mesma regra vale para os registros em arquivos digitais e em redes sociais.

Ademais, julgou-se que o conteúdo da conta em rede social não se encontra abrangido pelo sigilo de telecomunicação face aos herdeiros, conforme segue: "Também o sigilo de telecomunicação não é contrário à reivindicação da requerente. O herdeiro não é “outro", conforme a concepção do $\S 88$, art. 3 da TKG ${ }^{6}$, uma vez que ele entra plenamente na posição do testador". ${ }^{7}$ (ALEMANHA, 2018, online).

Por fim, reconheceu-se que o assim chamado Regulamento Geral de Proteção de Dados alemão (Datenschutz-Grundverordnung [DS-GVO]) protege apenas dados de pessoas vivas, não incidindo sobre os direitos dos herdeiros sobre dados da pessoa falecida:

Finalmente a reivindicação do demandante também não colide com o direito de proteção de dados pessoais. A corte deve aplicar aqui o Regulamento Geral de Proteção de Dados em vigor desde 25 de maio de 2018 (Datenschutz-Grundverordnung [DS-GVO]). Este não se opõe ao acesso dos herdeiros. Interesses da transmitente ligados ao direito de proteção de dados pessoais (Datenschutzrecht) não são afetados, uma vez que o Regulamento protege apenas pessoas vivas. ${ }^{8}$ (ALEMANHA, 2018, online, tradução livre).

Do que foi exposto por meio do contido no comunicado divuldado pelo Tribunal Federal de Karlsruhe, tem-se que referida corte concedeu pleno reconhecimento àquilo que passou a ser chamado de herança digital, posicionando-se, clara e decididamente, em favor do direito dos herdeiros terem acesso aos arquivos digitais e conteúdos de redes sociais da pessoa falecida, rechaçando por completo a defesa do Facebook.

\footnotetext{
${ }^{5}$ Eine Differenzierung des Kontozugangs nach vermögenswerten und höchstpersönlichen Inhalten scheidet aus. Nach der gesetzgeberischen Wertung gehen auch Rechtspositionen mit höchstpersönlichen Inhalten auf die Erben über. So werden analoge Dokumente wie Tagebücher und persönliche Briefe vererbt, wie aus § 2047 Abs. 2 und 2373 Satz 2 BGB zu schließen ist. Es besteht aus erbrechtlicher Sicht kein Grund dafür, digitale Inhalte anders zu behandeln.

${ }^{6}$ Lei de Telecomunicações alemã.

${ }^{7}$ Auch das Fernmeldegeheimnis steht dem Anspruch der Klägerin nicht entgegen. Der Erbe ist, da er vollständig in die Position des Erblassers einrückt, jedenfalls nicht "anderer" im Sinne von \$ 88 Abs. 3 TKG.

${ }^{8}$ Schließlich kollidiert der Anspruch der Klägerin auch nicht mit dem Datenschutzrecht. Der Senat hat hierzu die seit 25. Mai 2018 geltende Datenschutz-Grundverordnung (DS-GVO) anzuwenden. Diese steht dem Zugang der Erben nicht entgegen. Datenschutzrechtliche Belange der Erblasserin sind nicht betroffen, da die Verordnung nur lebende Personen schützt.
}

Revista Brasileira de Direito Civil em Perspectiva | e-ISSN: 2526-0243| Porto Alegre | v. 4 | n. 2 |

p. $136-155$ | Jul/Dez. 2018 


\section{HERANÇA DIGITAL E PRIVACIDADE}

O case acima narrado levanta uma questão de fundamental importância no que diz respeito à inviolabilidade das comunicações em face da chamada herança digital. Põe-se imediatamente a questão se o reconhecimento da herança digital comporta uma relativização de tal garantia fundamental ou apenas o reconhecimento de uma nova realidade trazida pela intensa dinâmica do avanço tecnológico.

Tal desafio está situado no contexto de uma ampla gama de situações novas que demandam respostas do direito. Vive-se atualmente numa sociedade líquida, num tempo líquido e, finalmente, numa modernidade líquida, fazendo-se referência às expressões cunhadas pelo sociólogo polonês Zygmunt Bauman (2001).

Passamos de uma modernidade sólida, onde tudo é estável, regular e repetitivo, para uma modernidade líquida, onde tudo é instável, irregular e fluido (MONTEALEGRE ITURRA, 2012, online).

É em resposta a esse quadro, marcado pelo pluralismo e pela fluidez, que atua o neoconstitucionalismo, o qual é uma moderna corrente de hermenêutica dos textos constitucionais e que compreende que nenhuma norma ou princípio constitucional, ainda que relativos a direitos ou garantias fundamentais, são absolutos, mas integram-se e harmonizamse mutuamente diante de determinado caso concreto (CAMBI, 2016, p. 352).

De acordo com essa perspectiva, os direitos fundamentais equivalem a princípios, ou melhor, são "comandos prima facie, pois, a exemplo dos princípios, somente no caso concreto será possível dimensionar as suas possibilidades jurídicas e fáticas" (CAMBI, 2016, p. 122). E, ainda quando externam normas precisas, com clara descrição do tipo de conduta que abarcam, podem ser considerados como tais, de forma que "mesmo os direitos fundamentais mencionados poderiam se sujeitar postulado (sic) da proporcionalidade. Somente a interpretação literal do conteúdo textual do art. 5º XXXVI, LVI e LXVII, permitiria considerar tais direitos fundamentais como regras" (CAMBI, 2016, p. 123).

A aplicação dos princípios ao caso concreto demanda, muitas vezes, um raciocínio de argumentativo de ponderação, uma vez que podem afigurar-se conflitos entre os princípios de mesma estatura possivelmente aplicáveis ao caso. Dessa forma, o julgador deverá buscar a

Revista Brasileira de Direito Civil em Perspectiva | e-ISSN: 2526-0243| Porto Alegre | v. 4 | n. 2 |

p. 136 - 155 Jul/Dez. 2018 
harmonização entre os princípios, mediante um balanceamento (balancing), indicando qual deles deve prevalecer e em que medida (CAMBI, 2016, p. 351).

Da leitura do inciso XII, do artigo $5^{\circ}$, da Lei Maior brasileira, pode-se extrair a conclusão de que a inviolabilidade do sigilo de dados e sua excepcionalidade somente para fins de investigação criminal e instrução do processo penal, constitui uma regra e não um princípio.

Porém, do que foi acima exposto, tal norma também pode sujeitar-se ao juízo de ponderação e ser considerada na qualidade princípio.

No caso da decisão da Corte Federal alemã, não se vislumbrou, ao se permitir o acesso dos herdeiros à conta da garota falecida, qualquer violação ao seu direito fundamental à privacidade, nem de terceiros que com ela se comunicaram via rede social. A transmissão dos direitos sobre a conta aos herdeiros também não encontrou qualquer obstáculo quando confrontada com as normas pertinentes do Código Civil alemão, da Lei de Telecomunicações alemã e demais normativas relativas ao caso.

Ressalte-se que mesmo no direito brasileiro a intransmissibilidade dos direitos da personalidade não é absoluta, sendo admitido aos sucessores o direito de pleitear que cesse a lesão ou ameaça, bem como a reparação da lesão, aos direitos da personalidade do sucedido, conforme preceitua o artigo 12, parágrafo único, do Código Civil pátrio, a seguir transcrito:

Art. 12. Pode-se exigir que cesse a ameaça, ou a lesão, a direito da personalidade, e reclamar perdas e danos, sem prejuízo de outras sanções previstas em lei.

Parágrafo único. Em se tratando de morto, terá legitimação para requerer a medida prevista neste artigo o cônjuge sobrevivente, ou qualquer parente em linha reta, ou colateral até o quarto grau. (BRASIL, 2002, online)

A esse respeito, Ives Gandra da Silva Martins (2002, p. 6, online) esclarece que o disposto no artigo acima transcrito constitui exemplo de transmissibilidade de um direito até então considerado indisponível:

Não se deve confundir, por outro lado, a intransmissibilidade com o direito do sucessor de defesa dos direitos do sucedido, em vida ou após o falecimento, nestes casos admitindo-se, inclusive, que a lei torne um direito indisponível "transmissível", como, por exemplo, o direito à imagem, pelo menos no que diz respeito à sua defesa. A titularidade dos filhos para defender a imagem paterna é exemplo de transmissibilidade de um direito indisponível. 
Resta, porém, evidente que a norma do artigo 12, do Código Civil, não serve como parâmetro de comparação com a hipótese de herança digital, com admissão de que os herdeiros possam até mesmo ter acesso às contas em redes sociais de uma pessoa falecida. Trata-se de exceção pontuda da regra de intransmissibilidade, cuja justificativa se baseia na defesa contra lesão a direito da personalidade da pessoa falecida.

No entanto, tramitaram perante o Congresso Nacional alguns projetos de leis que visam a alteração de dispositivos do Código Civil, a fim de permitir expressamente a transmissão aos herdeiros dos direitos dos usuários falecidos sobre as redes sociais. Trata-se do Projeto de Lei n. 4.847/2012 (BRASIL, 2012, online), o qual foi apensado ao Projeto de Lei n. 4.099/2012 (BRASIL, 2012, online). Há ainda o Projeto de Lei n. 1.331/2015 (BRASIL, 2015, online), que propõe a alteração da Lei do Marco Civil da Internet, com vistas a conceder aos herdeiros a legitimidade para promover a exclusão dos dados do herdeiro falecido.

Para Livia Teixeira Leal (2018, p. 190, online) a situação é amplamente complexa e a abordagem do assunto por meio de um viés patrimonial não é adequada, devendo-se fazer a distinção entre situações patrimoniais e existenciais na rede.

Para a autora as situações patrimoniais são as realidades dotadas de valor econômico ou que tenham algum tipo de repercussão em referido âmbito, ao passo que as existências são aquelas não dotadas de valor econômico, como muitas das realidades ligadas aos direitos da personalidade, que são instransmissíveis. Dentre essas últimas, enquadram-se os arquivos de redes sociais.

Não se pode ignorar que alguns direitos são personalíssimos, e, portanto, intransmissíveis, extinguindo-se com a morte do titular, não sendo objeto de sucessão, não integrando o acervo sucessório por ele deixado. Assim, como a herança refere-se ao acervo patrimonial do de cujus, as situações existenciais, ressalvadas as situações dúplices em alguns aspectos, não vão integrar o conceito de herança (LEAL, p. 191, online).

Para a autora, portanto, as conversas registradas em rede social não podem ser transmitidas por herança, por não se revestirem de conteúdo patrimonial, mas existencial. Somente quando elementos afetos aos direitos da personalidade forem dotados de caráter econômico é que poderá haver a sucessão. É o que ocorre, por exemplo, com senhas e dados bancários sigilosos, cujo acesso se mostra imprescindível a que os herdeiros tenham acesso ao patrimônio.

Revista Brasileira de Direito Civil em Perspectiva | e-ISSN: 2526-0243| Porto Alegre | v. 4 | n. 2 |

p. 136 - 155 Jul/Dez. 2018 
Assim, não há transmissão post mortem dos direitos da personalidade no direito brasileiro, e sim a tutela de um centro de interesses relacionado à personalidade, considerada valor, que pode se operar até mesmo em face de uma violação perpetrada pelos familiares do de cujus. Vale dizer: os dados pessoais dos usuários falecidos não são transferidos aos herdeiros, na medida em que se referem a aspecto existencial do de cujus.

Desse modo, permitir que a privacidade da pessoa falecida seja devassada pelos familiares, por meio do acesso irrestrito às suas contas digitais e a seus dados ali contidos, não parece ser uma solução compatível com o sistema jurídico vigente. É nesse sentido que a proposta de transmissão automática das contas do usuário falecido aos herdeiros esbarra na proteção de interesses existenciais deste, que não deixam de receber tutela jurídica após a sua morte (LEAL, p. 194, online).

Por outro lado, conforme assinala Claudio Luiz Bueno de Godoy (2005, p. 126), o domínio da privacidade é amplo e abrangente, podendo-se identificar, "como objeto do direito à privacidade, a tutela de dados da pessoa que digam com suas crenças (sic), confidências, pensamentos, hábitos, sua vida afetiva, familiar, negócios particulares”, rol este, não exaustivo, mas que no entanto, demonstra certa relatividade do domínio da privacidade, consoante prossegue o mesmo autor:

[...] qualquer apriorístico elenco de dados cobertos pelo direito à privacidade não esgota o que, afinal, é um conceito aberto, cujo conteúdo deve variar em função do titular da prerrogativa em exame e de sua situação, de sua inserção histórico-cultural. Por outra, não há um domínio fixo e estável em que se possa situar a privacidade, forçosamente relativizada pelas contingências subjetivas e objetivas, de espaço e tempo, que a circundam, ou que moldam a realidade em que ela se projeta. Na análise de Costa Andrade, não é possível, a priori, referenciar um universo de eventos ou experiências imutáveis e definitivamente marcantes da vida privada, ou que sejam a ela pertinentes. Haverá sempre uma flutuação material em função de quem seja o titular do direito e do ambiente em que ele se coloca (GODOY, 2005, p. 126).

Acrescente-se a tudo isso que a definição do domínio da privacidade de um sujeito depende inevitavelmente de sua própria subjetividade, à qual compete estabelecer o que deseja tornar público acerca de sua individualidade e o que não deseja.

Assim, conquanto possam haver situações de violação da privacidade claras e inequívocas e situações que sempre irão configurar tais violações, em outros casos somente a análise da situação concreta, em confronto com a subjetividade da vítima é que podem determinar a ocorrência ou não da violação, assim como grau de sua gravidade.

Para Paula Galato de Faveri (2014, p. 84, online), embora a personalidade se extinga com a morte, um núcleo de direitos relativos à personalidade permanece, sendo possível a sua 
transmissão com base em uma interpretação extensiva e lógica dos dispositivos do Código Civil.

Para a autora, inobstante não terem sido ainda aprovados projetos de lei que autorizem a herança digital, a tutela dos direitos relativos à herança digital já seria possível:

\begin{abstract}
Depreende-se, com isso, que, se por um lado os projetos de lei em foco têm a pretensão de incluir no ordenamento civil brasileiro o tema herança digital, a fim de regularem especificamente sobre essa situação, a hodierna ausência de tratamento específico sobre o legado virtual não implica na inexistência de um centro de interesses a ser tutelado juridicamente.

Sendo possível, para tanto, uma interpretação lógica e extensiva dos direitos sucessórios advindos do Código Civil de 2002, os quais estabelecem a quem se transmitirá a herança. Razão pela qual, caso não seja da vontade do usuário que os seus familiares tenham acesso aos seus dados privados virtuais, é de suma importância redigir um testamento virtual (FÁVERI, 2014, p. 82, online).
\end{abstract}

O caso da decisão do Tribunal Federal da Alemanha aponta ainda para outro aspecto no contexto da proteção à intimidade e da privacidade. Trata-se do aspecto referente à preservação da intimidade e da privacidade em âmbito familiar. Também nesse contexto, a intimidade e a privacidade merecem proteção em face dos outros membros da família. Até mesmo os filhos menores possuem direito à intimidade e à privacidade em relação aos pais.

No entanto, a situação se reveste de especial particularidade, conforme bem demonstra Claudio Luiz Bueno de Godoy (2005, p. 144):

A rigor, a exata definição dos lindes entre o exercício da autoridade parental e a privacidade dos filhos a ele sujeitos implica numa historicidade intrínseca, no permeio necessário dos dados específicos daquela situação familiar, o que deve ser ponderado em verdadeiro juízo de proporcionalidade, de resto tal como se aprecia a própria extensão, em geral, da vida privada das pessoas. Ponderam-se, enfim, de um lado o poder-dever que aos pais incumbe, no exercício do poder familiar, de fiscalizar, controlar, regrar, e por isso até restringir, a conduta dos filhos, mas sempre de modo a alcançar a sua melhor formação, e, de outro, a privacidade que, ao mesmo fim de promoção de sua dignidade, a estes menores o ordenamento garante. Portanto, o critério básico para este balanço está na verificação, sempre, do melhor interesse do menor, do devido respeito a sua dignidade, posto que para tanto por vezes se imponham, a seu bem, devidas limitações que, na realidade, definem o conteúdo de sua liberdade de escolha, de autodeterminação.

Embora tal aspecto não tenha ficado evidente no comunicado da decisão do Tribunal de Karlsruhe, percebe-se que o foi considerado no momento em que os pais deixaram de ser considerados como "outros". Com efeito, a família constitui parte do âmbito de intimidade e

Revista Brasileira de Direito Civil em Perspectiva | e-ISSN: 2526-0243| Porto Alegre | v. 4 | n. 2 |

p. 136 - 155 Jul/Dez. 2018 
privacidade de uma pessoa. Na consideração de acerca de uma possível violação, é possível ou até provável que a toda a família seja atingida, ainda que a vítima direta seja apenas um de seus membros. Por outro lado, atos que inegavelmente configuram violação de privacidade por parte de um estranho, não o configuram se praticado por um membro da família, uma vez que ela própria pertence ao âmbito da privacidade do sujeito.

\section{CONSIDERAÇÕES FINAIS}

A proteção da intimidade e da privacidade reveste-se de fundamental importância no contexto do Estado Democrático de Direito e a sua inviolabilidade constitui direito fundamental da pessoa humana, plenamente reconhecido em todo o mundo democrático. Por outro lado, a violação da intimidade e da privacidade é característica comum em regimes ditatoriais e totalitários.

O avanço tecnológico, especialmente na área de informática, recobra do direito respostas aos novos desafios, dentre os quais os relacionados ao tema da assim chamada "herança digital", ou seja, o direito que teriam os herdeiros de uma pessoa falecida de acesso aos seus dados e arquivos armazenados digitalmente, inclusive suas conversas armazenadas em redes sociais.

Conforme se depreendeu da análise da decisão do Tribunal Federal Alemão de Karlsruhe, que determinou ao Facebook a liberação aos pais do acesso integral à conta de sua filha na rede social, houve um claro reconhecimento do direito à "herança digital".

Foram rechaçados todos os argumentos do requerido que sustentavam que a liberação do acesso feriria o direito à privacidade da garota falecida e de terceiros com os quais ela se comunicou em vida. Afirmou-se, basicamente, que o vínculo contratual entre a garota e a rede social transferiu-se aos herdeiros e que o acesso destes às suas conversas é equivalente ao acesso a possíveis registros escritos que tenha deixado em diários, anotações e cartas.

No entanto, da análise do direito positivo, especialmente do contido na Constituição Alemã, verificou-se que o dispositivo referente à inviolabilidade de comunicações constitui-se de preceito amplamente mais aberto que o dispositivo correlato da Constituição Brasileira, a

Revista Brasileira de Direito Civil em Perspectiva | e-ISSN: 2526-0243| Porto Alegre | v. 4 | n. 2 |

p. $136-155$ | Jul/Dez. 2018 
qual só prevê exceções para o princípio para fins de investigação criminal, sendo que os dispositivos da Lei do Marco Civil da Internet (Lei n. 12.965/14) seguem a mesma linha.

Embora a decisão do Tribunal Federal Alemão possa influenciar decisões semelhantes em outros países, é de se concluir, no entanto, que o reconhecimento da "herança digital" venha a passar por maiores dificuldades no Brasil, haja vista o maior rigor com que o ordenamento jurídico brasileiro trata do tema. Soma-se a isso a controvérsia existente na doutrina e no debate acadêmico acerca do assunto.

Acresce-se também que, especificamente com relação às conversas armazenadas em redes sociais, pela exegese do art. $10, \S \S 1^{\mathrm{o}}$ e $2^{\mathrm{a}}$, da Lei do Marco Civil da Internet se conclui que às redes sociais não se obriga o armazenamento dessas conversas.

Por fim, ainda que sejam aprovadas leis que venham a autorizar a transmissão por herança dos conteúdos de arquivos digitais e conteúdos de contas em redes sociais, é certo que não irá esmorecer o debate sobre sua adequação ou não ao regime de proteção da intimidade e da privacidade previstos na Constituição, uma vez que tais direitos não possuem caráter patrimonial e, portanto, hereditário, além de serem irrenunciáveis e intransmissíveis e que a proteção da intimidade e da privacidade transcendem à morte do indivíduo.

\section{REFERÊNCIAS}

ALEMANHA. Lei Fundamental da República Federal da Alemanha. Disponível em: <https://www.btg-bestellservice.de/pdf/80208000.pdf>. Acesso em: 03 set. 2018.

- German Civil Code. Disponível em: <http://www.fd.ulisboa.pt/wpcontent/uploads/2014/12/Codigo-Civil-Alemao-BGB-German-Civil-Code-BGB-englishversion.pdf> Acesso em: 8 set. 2018.

Telekommunikationsgesetz (TKG). Disponível em: <https://www.gesetze-iminternet.de/tkg_2004/TKG.pdf >. Acesso em: 8 set. 2018.

. Tribunal Federal. Mitteilung der Pressestelle. Verhandlungstermin am 21. Juni 2018, 10.00 Uhr, Saal N 004 (Saalwechsel vorbehalten) - III ZR 183/17 (Zugang von Erben auf das Konto eines verstorbenen Nutzers eines sozialen Netzwerks). Disponível em: < https://juris.bundesgerichtshof.de/cgibin/rechtsprechung/document.py?Gericht=bgh\&Art=en\&Datum=20187\&anz=17\&pos=2\&nr=80925\&linked=pm\&Blank=1 > . Acesso em: 3 set. 2018.

. Tribunal Federal. Mitteilung der Pressestelle. Vertrag über ein Benutzerkonto bei einem sozialen Netzwerk ist vererbbar. Disponível em: <

Revista Brasileira de Direito Civil em Perspectiva | e-ISSN: 2526-0243| Porto Alegre | v. 4 | n. 2 |

p. 136 - 155 Jul/Dez. 2018 
https://juris.bundesgerichtshof.de/cgi-

bin/rechtsprechung/document.py?Gericht=bgh\&Art=en\&Datum=2018-

$7 \&$ anz $=17 \&$ pos $=2 \& n r=85390 \& l i n k e d=$ pm\&Blank=1 $>$. Acesso em: 3 set. 2018.

ALONSO, Félix Ruiz. Pessoa, intimidade e o direito à privacidade. In: MARTINS, Ives Gandra da Silva; MONTEIRO JUNIOR, Antonio Jorge, (coordenadores). Direito à privacidade. Aparecida, SP: Idéias \& Letras; São Paulo: Centro de Extensão Universitária, 2005. p. 11-35.

BAUMAN, Zygmunt. Modernidade líquida. Tradução de Plínio Dentzien. Rio de Janeiro, Jorge Zahar Editor, 2001.

BRASIL. Código Civil. Disponível em: <http://www.planalto.gov.br/ccivil_03/leis/2002/110406.htm>. Acesso em: 3 set. 2018.

Constituição da República Federativa do Brasil de 1988. Disponível em: <http://www.planalto.gov.br/ccivil_03/Constituicao/Constituicao.htm>. Acesso em: 3 set. 2018.

Lei n. 12.965, 23 abr. 2014. Disponível em: <http://www.planalto.gov.br/ccivil_03/_ato2011-2014/2014/lei/112965.htm>. Acesso em: 3 set. 2018.

CAMBI, Eduardo. Neoconstitucionalismo e Neoprocessualismo: direitos fundamentais, políticas públicas e protagonismo judiciário. São Paulo: Almedina, 2016. 727 p.

FACEBOOK. Solicitação de memorial. Disponível em: <https://www.facebook.com/help/contact/651319028315841 >. Acesso em: 3 set. 2018.

FÁVERI, Paula Galatto de. Herança digital no Brasil: uma análise dos direitos da personalidade após a morte quanto aos arquivos deixados na internet. 2014. $100 \mathrm{f}$. Monografia (Especialização) - Curso de Direito, Universidade do Extremo Sul Catarinense, Criciúma-sc, 2014. Disponível em: <http://repositorio.unesc.net/handle/1/3371>. Acesso em: 08 set. 2018.

GODOY, Cláudio Luiz Bueno de. O direito à privacidade nas relações familiares. In: MARTINS, Ives Gandra da Silva; MONTEIRO JUNIOR, Antonio Jorge, (coordenadores). Direito à privacidade. Aparecida, SP: Idéias \& Letras; São Paulo: Centro de Extensão Universitária, 2005. p. 119-148.

JABUR, Gilberto Haddad. A dignidade e o rompimento de privacidade. In: MARTINS, Ives Gandra da Silva; MONTEIRO JUNIOR, Antonio Jorge, (coordenadores). Direito à privacidade. Aparecida, SP: Idéias \& Letras; São Paulo: Centro de Extensão Universitária, 2005. p. 85-106.

LEAL, Livia Teixeira. Internet e morte do usuário: a necessária superação do paradigma da herança digital. Revista Brasileira de Direito Civil - RBDCilvil, Belo Horizonte, v. 16, p. 181-

Revista Brasileira de Direito Civil em Perspectiva | e-ISSN: 2526-0243| Porto Alegre | v. 4 | n. 2 |

p. $136-155$ | Jul/Dez. 2018 
197, abr./jun. 2018. Disponível em: 〈https://rbdcivil.ibdcivil.org.br/rbdc/article/view/230>. Acesso em: 8 set. 2018.

LOPES, Marcelo Frullani. O sigilo das comunicações no marco civil da internet. Disponível em: <http://justificando.cartacapital.com.br/2016/04/07/o-sigilo-das-comunicacoes-no-marcocivil-da-internet/>. Acesso em: 30 ago. 2018.

MARTINS, Ives Gandra da Silva. Os direitos da personalidade. Disponível em: $<$ http://www.gandramartins.adv.br/project/ives-

gandra/public/uploads/2013/02/04/e31ef8ba2002115_homenagem_miguel_reale.pdf>.

Acesso em: 3 set. 2018.

MONTEALEGRE ITURRA, Jorge. Archipiélagos virtuales: Internet y registros de memorias en la sociedad líquida. Polis, Santiago, v. 11, n. 32, p. 399-422, agosto 2012 . Disponível em: <https://scielo.conicyt.cl/scielo.php?script=sci_arttext\&pid=S071865682012000200019\&lng=es\&nrm=iso>. Acesso em: 05 set. 2018.

PEIXOTO, Erick Lucena Campos; EHRHARDT JÚNIOR, Marcos. Breves notas sobre a ressignificação da privacidade. Revista Brasileira de Direito Civil - RBDCilvil, Belo Horizonte, v. 16, p. 35-56, abr.jun. 2018. Disponível em: <https://rbdcivil.ibdcivil.org.br/rbdc/article/view/230/212 >. Acesso em: 8 set. 2018.

VIEIRA DE LORENZI CANCELIER, Mikhail. O direito à privacidade hoje: perspectiva histórica e o cenário brasileiro. Seqüência: Estudos Jurídicos e Políticos, Florianópolis, v. 38, n. 76, p. 213-240, set. 2017. ISSN 2177-7055. Disponível em: <https://periodicos.ufsc.br/index.php/sequencia/article/view/2177-7055.2017v38n76p213 >.

Acesso em: 08 set. 2018. 